\title{
Produção de embriões bovinos in vitro com sêmen sexado
}

\section{In vitro production of bovine embryos with sex-sorted semen}

\section{Resumo}

Com o advento da sexagem espermática a escolha do sexo da prole se tornou uma grande vantagem, principalmente para os criadores de gado leiteiro, que necessitam de novas matrizes para a manutenção do seu rebanho e para os criadores de gado de corte, que almejam mais machos para a produção de carne. Atualmente, a única técnica conhecida capaz de separar as populações de espermatozoides $X$ e $Y$ de mamíferos, com eficiência e pureza acima de $90 \%$, é a citometria de fluxo. A melhor forma de uso do sêmen sexado é na fertilização in vitro, devido ao reduzido número de espermatozoides disponíveis após a sexagem. Vários fatores podem influenciar os resultados da produção in vitro de embriões na espécie bovina utilizando sêmen sexado; dentre eles destacam-se as baixas taxas de fertilização, de clivagem, de blastocistos, de gestações; capacitação espermática parcial; amostras seminais diluídas e a variação entre touros. Alguns estudos têm sido realizados com o intuito de avaliar as alterações genéticas e epigenéticas decorrentes do uso do sêmen sexado na produção de embriões bovinos in vitro. Portanto, este trabalho tem como objetivo realizar uma revisão de literatura sobre as limitações e as vantagens do uso do sêmen sexado, com ênfase na técnica de citometria de fluxo, durante a produção embrionária in vitro na espécie bovina.

\section{Summary}

The advent of sex-sorting-sperm sex selection of offspring became a great advantage, especially for dairy farms, which need new heifers for maintenance of his herds, and for beef cattle breeders, who crave more males for meat production. Currently, the only known technique capable of separating the populations of $X$ and $Y$ mammals sperm cells with efficiency and purity above $90 \%$ is flow cytometry. The best way of using sexed semen is in vitro fertilization, due to the small number of available sperm after sexing. Several factors can influence the results of in vitro embryos production using bovine sexed semen; among them there are the low rates of fertilization, cleavage, blastocyst, pregnancies, partially sperm capacitation, diluted semen samples and variation among bulls. Several studies have been conducted in order to assess the genetic and epigenetic alterations resulting from the use of sexed semen in the production of bovine embryos in vitro. Therefore, this paper aims to conduct a literature review on the limitations and advantages of using sexed semen, with emphasis on the technique of flow cytometry, during in vitro embryo production in cattle. 
Michelle Silva Araujo ${ }^{1}$

Rodrigo Volpato ${ }^{2}$

Maria Denise Lopes ${ }^{3}$
Rua Waldemar Rosa, $n^{\circ} 167$, Vila Shangri-lá, CEP: 18.608-401, Botucatu-SP, Brasil

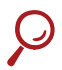

\section{Palavras-chave}

Bovino. Sêmen sexado.

Fertilização in vitro. Expressão gênica.

\section{Keywords}

Sexed semen. In vitro fertilization.

Gene expression

\section{Introdução}

Com o intuito de manter um lugar de destaque como maior exportador mundial de carne bovina e estimular o desenvolvimento da produção leiteira, várias biotecnologias reprodutivas estão sendo empregadas no setor pecuário brasileiro (LUCHIARI FILHO, 2006; SIQUEIRA; CARNEIRO, 2012). Dentre essas, a produção de embriões in vitro (PIV) tem contribuído de maneira significativa para o aumento da produção de animais em menor espaço de tempo, além de promover melhora zootécnica e agregar valor ao rebanho nacional.

Com o advento da sexagem espermática, a escolha do sexo da prole se tornou uma grande vantagem, principalmente para os criadores de gado leiteiro, que necessitam de novas matrizes para manutenção do seu rebanho e para os criadores de gado de corte, que almejam mais machos para a produção de carne (MOORE; THATCHER, 2006; TRIGAL et al., 2012). Além disso, a sexagem espermática permite rápido progresso genético, alta produtividade, melhora no bem-estar dos animais ao evitar castrações e reduz o impacto ambiental por restringir o nascimento de animais de sexo indesejado (RATH; JOHNSON, 2008). Entretanto, para que a técnica de sexagem possa ser extensivamente aplicada é necessário que seja barata, eficaz e eficiente, resultando em taxa de fertilidade igual ou superior à do sêmen não sexado (FOOTE; MILLER, 1971). Desta forma, essa tecnologia aliada à transferência de embriões e a

1 Mestranda da Faculdade de Medicina Veterinária e Zootecnia, Departamento de Reprodução Animal e Radiologia Veterinária - UNESP/Botucatu

2 Doutorando da Faculdade de Medicina Veterinária e Zootecnia, Departamento de Reprodução Animal e Radiologia Veterinária - UNESP/Botucatu

3 Professora Titular da Faculdade de Medicina Veterinária e Zootecnia, Departamento de Reprodução Animal e Radiologia Veterinária - UNESP/Botucatu 
programas de melhoramento genético, pode aumentar a rentabilidade da produção nacional de carne e leite (SEIDEL JR., 2003).

Atualmente, a técnica mais utilizada capaz de separar as populações de espermatozóides X e Y de mamíferos com eficiência e sensibilidade acima de $90 \%$, produzindo animais cujo sexo é condizente com o da população seminal sexada, é a citometria de fluxo (JOHNSON; FLOOK; HAWK, 1989). Entretanto, esta técnica de sexagem e a criopreservação espermática afetam a qualidade do sêmen de touros; além de as taxas de fertilização com sêmen sexado bovino serem 10 a $20 \%$ mais baixas quando comparadas à PIV com sêmen não sexado e à inseminação artificial convencional (SEIDEL JR. et al., 1999).

Embriões PIV apresentam diferenças na sua morfologia, tempo de desenvolvimento e no seu metabolismo, comparados aos embriões produzidos in vivo. Alterações são observadas no padrão normal de desenvolvimento dos embriões PIV produzidos com sêmen sexado, podendo estar relacionadas com diferenças em nível molecular dos embriões (MORTON et al., 2007).

Desvios no padrão normal de expressão do RNA mensageiro (mRNA), observados em embriões antes de sua implantação, podem persistir durante todo o desenvolvimento fetal e ao nascimento, uma vez que os efeitos de um dado procedimento podem não se manifestar durante um período relativamente curto do cultivo in vitro (WRENZYCKI et al., 2005).

Destarte, o objetivo deste trabalho foi a realização de uma revisão de literatura sobre as limitações e as vantagens do uso do sêmen sexado, com ênfase na técnica de citometria de fluxo, durante a produção embrionária in vitro na espécie bovina.

\section{Revisão de Literatura}

\section{Técnica de sexagem espermática}

No início do século XX a determinação do sexo era somente atribuída ao cromossomo $\mathrm{X}$, sendo o macho classificado como XO e a fêmea XX. Foi então que em 1914, Bridges descobriu que o sexo masculino era determinado pela associação do cromossomo X com outro morfologicamente distinto, o qual foi denominado Y. Sendo assim, a separação dos espermatozoides que contém o cromossomo $\mathrm{X}$ daqueles que contém o $\mathrm{Y}$ tornou-se possível por meio da detecção de antígenos de superfície, gradiente de densidade ou pelo conteúdo de DNA (MOTA, 2004; LIMA, 2006).
Em 1955, o antígeno $\mathrm{H}-\mathrm{Y}$ foi descrito pela primeira vez por Eichwald e Silmser como sendo um antígeno específico relacionado ao sexo masculino (HENDRIKSEN, 1999). Os peptídeos H-Y são apresentados como um grande complexo de histocompatibilidade de moléculas sobre a superfície da célula, tornando possível a sexagem dos espermatozoides em larga escala pelas proteínas de superfície por anticorpos específicos, antiespermatozoide $\mathrm{X}$ e antiespermatozoide $\mathrm{Y}$ (HENDRIKSEN, 1999). Peter, Jones e Robinson (1993) relataram que a separação dos espermatozoides X e Y pode chegar à acuidade de $98 \%$, utilizando anticorpos monoclonais anti-H-Y associados a cotas de polímeros magnetizados.

A centrifugação em gradiente de densidade baseia-se na diferença de densidade existente entre os cromossomos X e Y (LIMA, 2006). Analisando-se a cabeça dos espermatozoides pela técnica de microinterferometria, foi verificado que o cromossomo X contém maior conteúdo de DNA e proteína nuclear que os espermatozoides $\mathrm{Y}$, o que causa diferença de peso e, consequentemente, de densidade entre os dois tipos celulares (SUMNER; ROBINSON, 1976). As injúrias causadas aos espermatozoides pelas sucessivas centrifugações e manipulações podem ser minimizadas pela diminuição do número de centrifugações, pois não é alterada a acurácia da separação dos espermatozoides $\mathrm{X}$ e $\mathrm{Y}$, preservando-se a sua resistência ao processo de congelação (LIMA, 2006).

Até a década de oitenta, um dos problemas observados nos procedimentos de FIV era a ausência de um método preciso e prático que diferenciasse o cromossomo sexual dos espermatozoides (GARNER; SEIDEL JR., 2008).

A utilização do citômetro de fluxo, criado no laboratório "Lawrence Livermore National Laboratory" (LLNL), por Daniel Pinkel (PINKEL et al., 1982), com a finalidade de auxiliar o estudo dos efeitos da radiação na saúde humana, usando como modelo indicativo de dano ao DNA de espermatozoides de ratos, foi um grande avanço para a sexagem espermática (GARNER; SEIDEL JR., 2008). O aprimoramento desta técnica e a sua utilização tornaram possível a sexagem precisa dos espermatozoides X e Y, baseando-se na diferença do conteúdo do DNA (GARNER; SEIDEL JR., 2008). Na análise do sêmen de bovinos pela citometria de fluxo, o cromossomo $\mathrm{X}$ apresentou $3,8 \%$ a mais de DNA quando comparado ao cromossomo Y (ZHANG; LU; SIEDEL, 2003).

Apesar de ter sido demonstrado que a técnica de citometria de fluxo é capaz de permitir a determinação precisa do cromossomo $\mathrm{X}$ ou $\mathrm{Y}$ no ejaculado de diversas espécies como bovinos, ovinos, suínos e 
coelhos; esse método inviabilizava o espermatozoide ao torná-lo permeável ao corante de membrana fluorescente 4'-6-diamindino-2-fenilindole (GARNER et al., 1938).

Com a finalidade de preservar a célula espermática, outro corante de DNA permeável à membrana plasmática - bisbenzimidazol fluorescente - Hoechst 33342 passou a ser empregado, o qual atua ligando-se seletivamente às regiões ricas em DNA e permite a detecção de pequenas diferenças no seu conteúdo (JOHNSON et al., 1987; KLINC; RATH, 2006).

Para a realização da sexagem espermática pelo citômetro de fluxo o espermatozoide corado com Hoechst 33342 é bombardeado com um raio laser de comprimento de onda específico e é emitido um brilho azul fluorescente. Essa fluorescência é rapidamente mensurada por um tubo fotomultiplicador e um computador de alta velocidade é utilizado para analisar a fluorescência relativa emitida pelos espermatozóides $\mathrm{X}$ e $\mathrm{Y}$. Um cristal vibrador quebra o curso do sêmen em gotas individuais contendo vários espermatozoides, os quais são corados pela fluorescência e classificados de acordo com o conteúdo de DNA pela colocação de cargas opostas nas gotas contendo espermatozoides X ou Y. As gotas passam por campos elétricos negativos e positivos, e uma vez que as cargas opostas se atraem, as gotas se separam em dois fluxos para coleta. Um terceiro fluxo contendo gotas sem carga, gotas contendo espermatozoides que não foram sexados com precisão, gotas sem espermatozoides ou que possuem dois espermatozoides ou contendo gotas com espermatozoides inviáveis, são descartadas. O descarte dos inviáveis é uma grande vantagem da técnica (GARNER; SEIDEL JR., 2008).

A qualidade do ejaculado influencia diretamente a velocidade do processo de sexagem, que por sua vez interfere diretamente na pureza do sêmen. No que concerne à eficiência do processo de sexagem pela técnica de citometria de fluxo, em condições ótimas, no período de uma hora podem ser produzidas dez doses de sêmen sexado de bovinos na concentração de $2 \times 10^{6}$ espermatozoides por dose para ambos os sexos (GARNER, 2006). No entanto são necessários, atualmente, cerca de nove minutos para se produzir uma palheta de sêmen sexado, que se traduz em aproximadamente sete palhetas por hora na concentração de $2 \times 10^{6}$ espermatozoides por dose (GARNER; SEIDEL JR., 2008). A velocidade de separação é geralmente de 3.000 a 4.000 células vivas por segundo com acurácia de, em média, 90\%; o que já é considerado um grande avanço se comparado aos resultados obtidos há alguns anos atrás (SEIDEL JR., 2003).

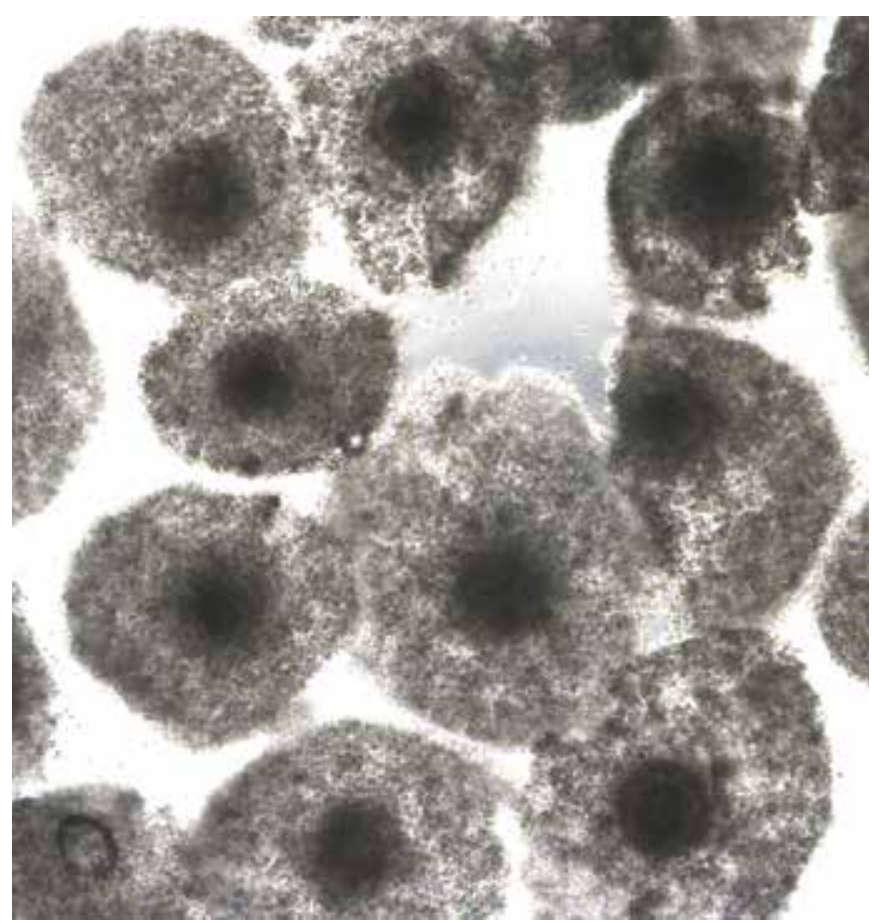

FIGURA 1 - Oócitos bovinos grau 1/grau 2 após 24 horas de maturação in vitro em estufa com $5 \%$ de $\mathrm{CO} 2$

\section{Produção de embriões bovinos in vitro com sêmen sexado}

A melhor forma para uso do sêmen sexado é na FIV, devido ao reduzido número de espermatozoides disponíveis após a sexagem (GARNER; SEIDEL JR., 2008). Vários fatores podem influenciar os resultados de PIV na espécie bovina utilizando-se o sêmen sexado (WHEELER et al., 2006) destacando-se as baixas taxas de: fertilização, (CRAN; JOHNSON; POLGE, 1995), clivagem (LU; GRAN; SEIDEL, 1999), blastocistos (MERTON et al., 1997; LU; GRAN; SEIDEL, 1999), gestações (CRAN; JOHNSON; POLGE, 1995) e capacitação espermática parcial, assim como amostras seminais diluídas (LU; SEIDEL JR., 2004), bem como, a variação entre touros (ZHANG; LU; SEIDEL, 2003).

Palma et al. (2008) analisaram a motilidade progressiva do sêmen sexado, bem como as taxas de PIV e de desenvolvimento e a ultraestrutura dos blastocistos. Constataram que as taxas de clivagem, de desenvolvimento de blastocistos no dia sete e de motilidade progressiva seminal foram significativamente inferiores para o sêmen sexado em relação ao grupo controle. Verificaram também que os blastocistos fertilizados com sêmen sexado apresentaram diferenças ultraestruturais indicativas de apoptose ou de padrões de transcrição aberrantes. Os grupos fertilizados com sêmen sexado apresentaram proporção significantemente maior de mitocôndrias 
imaturas $(33,7 \%)$ em relação ao grupo controle $(21,6 \%)$. Além disso, o núcleo dos blastocistos produzidos com sêmen sexado apresentou menor porcentagem de membranas nucleares intactas $(33,3 \%)$ que os blastocistos do grupo controle $(4,2 \%)$. Também foi descrita alta contaminação dos meios de cultivos de embriões fertilizados com sêmen sexado, sendo as taxas de desenvolvimento dos blastocistos significativamente mais baixas para oócitos fertilizados com sêmen sexado quando as repetições contaminadas por microorganismos foram incluídas $(10,4 \%)$ ou excluídas $(15,7 \%)$ e comparadas ao grupo controle $(33,6 \%)$. Embora não se conheça a fonte da contaminação, assumiram que a mesma poderia estar associada à técnica de sexagem ou ao manuseio do sêmen.

A combinação do corante fluorescente à luz do laser de alta energia, utilizada durante a técnica de sexagem, pode reduzir a capacidade de fertilização dos espermatozoides sexados (PALMA et al., 2008). Entretanto Palma et al. (2008) encontraram alta taxa de blastocistos produzidos com sêmen sexado em um dos touros utilizados. Também foi verificado desenvolvimento embrionário adequado em outros dois grupos fertilizados com sêmen sexado, demonstrando-se assim que o sêmen bovino sexado descongelado pode ser utilizado em programas de FIV.

Wilson et al. (2006) observaram que embriões PIV viáveis fertilizados com sêmen sexado foram cultivados com sucesso até os dias sete e oito pós-fertilização, sendo

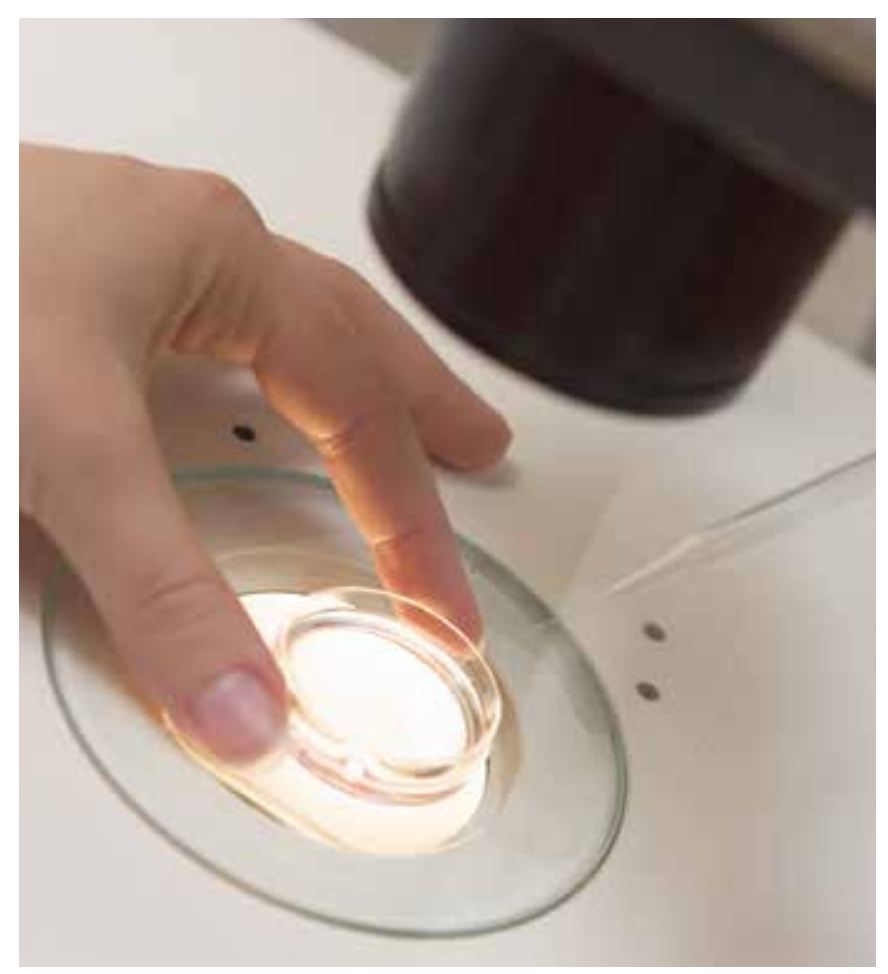

FIGURA 2 - Procedimento de visualização de embriões posteriormente transferidos para vacas receptoras, produzindo descendentes viáveis. Entretanto, foi necessário o emprego de um maior número de oócitos para se produzir o mesmo número de embriões quando comparado ao sêmen não sexado. Porém, as taxas de clivagem foram similares para PIV com sêmen não sexado e sexado, demonstrando que este último parece não prejudicar a fertilização do oócito; apenas promove impacto negativo no desenvolvimento embrionário.

Bermejo-Álvarez et al. (2008) observaram que a utilização do sêmen sexado na FIV apresentou baixa fertilidade e promoveu redução no desenvolvimento embrionário, comparado com o sêmen não sexado; sendo tais eventos geralmente atribuídos ao efeito deletério do procedimento de sexagem do sêmen sobre a capacitação e meia vida dos espermatozoides, corroborando com a afirmação de Maxwell et al. (2004).

Zhang, Lu e Seidel (2003) compararam o desenvolvimento de embriões bovinos produzidos in vitro após fertilização dos oócitos com três diferentes tipos de amostras seminais provenientes de três touros: sêmen apenas corado pelo corante Hoescht 33342, sêmen não sexado e não corado e sêmen sexado pela citometria de fluxo. Não foi constatada diferença significativa na taxa de desenvolvimento de blastocistos por oócito fertilizado entre os três tratamentos seminais, demonstrando que os sistemas de FIV com sêmen sexado podem ser realizados com êxito. Porém, as taxas de clivagem com sêmen sexado e sêmen corado não sexado foram mais baixas que as do grupo controle. Além disso, houve redução no desenvolvimento embrionário do grupo sêmen corado e sêmen sexado.

Lu, Gran e Seidel Jr. (1999) analisando o sêmen sexado e não sexado proveniente de cinco touros não encontraram diferença no desenvolvimento dos blastocistos fertilizados com ambos os tipos seminais; entretanto Zhang, Lu e Seidel (2003) demonstraram variação entre touros nas taxas de clivagem e de desenvolvimento dos embriões quando utilizaram sêmen sexado.

\section{Expressão gênica de embriões bovinos PIV com sêmen sexado}

Após o processo de maturação oocitária e de fertilização, o desenvolvimento embrionário antes da implantação é caracterizado por várias fases distintas, incluindo a primeira clivagem, ativação do genoma embrionário, compactação e formação do blastocisto (WRENZYCKI; HERRMANN; NIEMANN, 2007). Essas mudanças requerem sincronização adequada na expressão de genes derivados dos genomas maternos e/ou embrionários (KIDDER, 1992). A maior ativação do genoma embrionário 
bovino ocorre no estágio de oito a 16 células (TELFORD; WATSON; SCHULTZ, 1990), mas pequena ativação é observada antes mesmo do estágio embrionário de uma célula (MEMILI; FIRST, 2000).

$\mathrm{O}$ ambiente in vitro promove profundos efeitos nos padrões de expressão do mRNA de embriões bovinos antes de sua implantação, uma vez que os meios rotineiramente utilizados não são capazes de mimetizar de forma fidedigna um ambiente in vivo (WRENZYCKI et al., 2005). Quando a regulação epigenética da expressão do embrião é particularmente vulnerável a fatores externos, a possibilidade de comparar os padrões de expressão do mRNA entre embriões PIV e embriões produzidos in vivo em momentos críticos do seu desenvolvimento (como antes da implantação embrionária e durante a transição materno/fetal), torna-se um instrumento bastante importante (DEAN et al., 2001).

Genes conhecidos por desempenhar papéis importantes durante o desenvolvimento pré e pós-implantação tem sido investigados (WRENZYCKI et al., 2005). Estes genes estão envolvidos em vários processos biológicos, incluindo compactação e formação do blastocisto (E-cad, galectin-1, fribronectin, filamin A) (MOHAN; HURST; MALAYER, 2004), metabolismo (hormônio do crescimento, receptor do hormônio do crescimento e seu fator Pit-1 de transcrição) (JOUDREY et al., 2003), fator de crescimento/sinalizador de citocina (Fatores de crescimento semelhantes à insulina-IGF, receptores e proteinas ligantes IGF-I, IGF-II, IGF-IR, IGF-IIR, IGFBP1-6) (BERTOLINI et al., 2002), adaptação ao estresse (proteína do choque térmico 70.1), função trofoblástica (interferon-tau) (WRENZYCKI et al., 1999), transcrição e tradução (fatores gerais e específicos $Y Y_{1}, H M G A 1, R Y-1, p 300, C R E B$ ) (VIGNEAULT et al., 2004), regulação epigenética da transcrição (Dnmt1) (WRENZYCKI; NIEMANN, 2003) e apoptose (Bax, Bcl-xl, Xiap) (AUGUSTIN et al., 2003; JIMENEZ et al., 2003; GUTIÉRREZ-ÁDAN et al., 2004). Genes codificados dos cromossomos X (Xist) (WRENZYCKI et al., 2002) e Y (gene determinante do sexo da região Y) (GUTIÉRREZ-ÁDAN et al., 1997) também têm sido investigados.

Tem sido relatado que embriões produzidos com espermatozoide sexado podem ser de pior qualidade, baseado na redução do número de células (BEYHAN; JOHNSON; FIRST, 1999), redução no tempo de desenvolvimento (LU; CRAN; SEIDEL JR., 1999) e diferenças na quantidade de mRNA (MORTON et al., 2007).

Para melhor investigar o efeito do sêmen sexado na qualidade embrionária, Bermejo-Álvarez et al. (2010) analisaram a quantidade de mRNA em vários genes nos blastocistos bovinos de mesmo sexo produzidos com sêmen sexado e não sexado. Foram avaliados genes

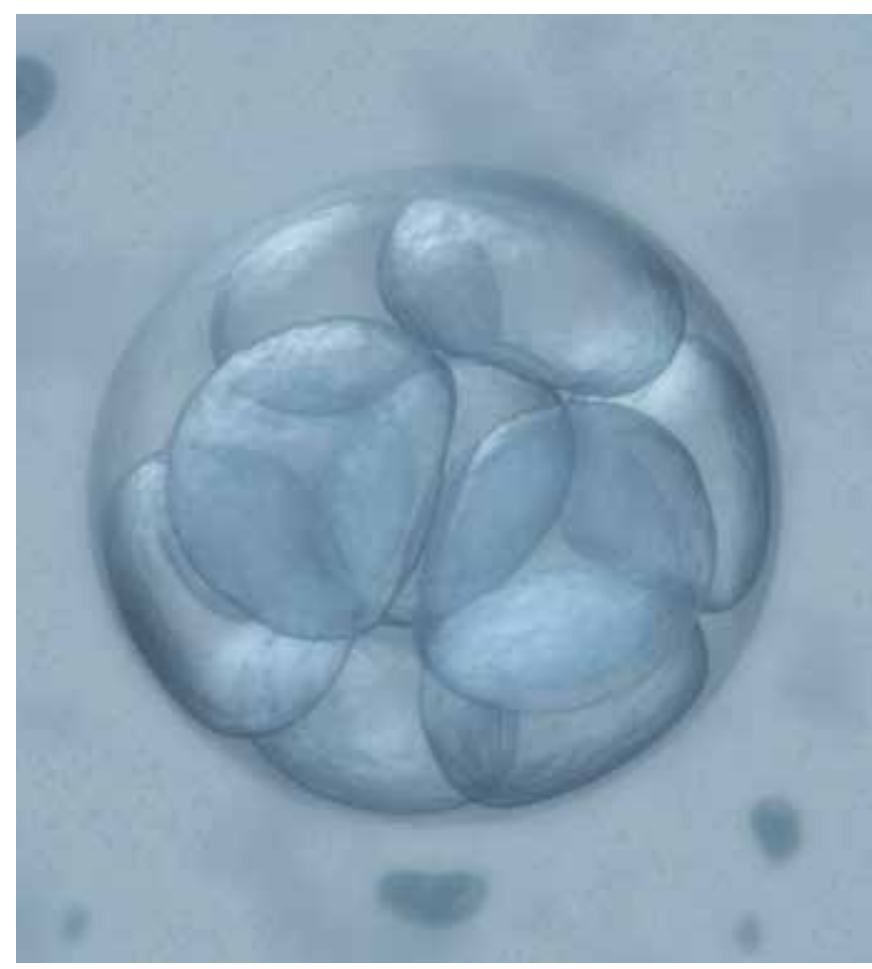

FIGURA 3 - Representação em 3D de célula embrionária

relacionados à apoptose $\left(T_{53}\right.$ e $\left.B A X\right)$, um gene envolvido com a detoxificação de radicais livres induzido pelo ultravioleta $\left(G S T M_{3}\right)$, cinco genes relacionados com o reconhecimento gestacional e formação placentária (PGRMC1, $C O X 2, A K R 1 B 1, I G F R 2$ e PLAC8) e um gene relacionado com a metilação do DNA no desenvolvimento embrionário inicial. Não foram encontradas diferenças na expressão gênica entre os blastocistos do mesmo sexo fertilizados tanto com sêmen sexado quanto com sêmen não sexado. Entretanto, três genes (GSTM3, DNMT3 A e PGRMC1) foram significativamente diferentes entre blastocistos macho e fêmea, para ambos os tipos seminais, sendo os genes $G_{S T M}$ e PGRMC1 mais expressos em embriões do sexo feminino e o $D N M T_{3} A$ em embriões do sexo masculino. Estes resultados demonstram que a produção de embriões com sêmen sexado e não sexado apresentam os mesmos padrões de expressão gênica sexo-específica, validando a utilização do sêmen sexado para a produção embrionária.

\section{Considerações Finais}

A utilização do sêmen sexado é de grande valia para a maior produção de animais de um determinado sexo e para a realização de estudos relacionados às diferenças de desenvolvimento de embriões machos e fêmeas. Entretanto, as taxas de fertilização in vivo e in vitro ainda não são melhores que às do sêmen não sexado. 
A técnica de sexagem espermática mais utilizada atualmente é a citometria de fluxo, porém é um processo muito demorado, pois é necessário longo tempo para ser sexado um pequeno volume de espermatozoides. Desta forma, apesar de vários criadores almejarem a utilização do sêmen sexado dentro do programa de reprodução de seu rebanho, o capital necessário para a implementação desta técnica ainda é alto.

A preparação e a manipulação do sêmen antes e após a sexagem interferem na qualidade seminal e, consequentemente, na fertilidade, apresentando menores taxas de desenvolvimento embrionário comparados ao sêmen não sexado. O touro parece exercer influência na qualidade do sêmen sexado e, portanto, na PIV.

A produção embriões com sêmen sexado durante a PIV, com relatos de nascimento de bezerros normais após a transferência dos embriões tem sido obtida sem que ocorram alterações na expressão de determinados genes relacionados ao desenvolvimento embrionário normal quando usam o sêmen sexado na FIV.

Novos trabalhos são necessários para melhor esclarecer a influência do sêmen sexado pelo método de citometria de fluxo na PIV.

\section{Referências}

1. AUGUSTIN, R.; POCAR, P.; WRENZYCKI, C.; NIEMANN, H.; FISCHER, B. Mitogenic and anti-apoptotic activity of insulin on bovine embryos produced in vitro. Reproduction, v. 126, p. 91-99, 2003.

2. BERMEJO-ÁLVAREZ, P.; RIZOS, D.; RATH, D.; LONERGAN, P.; GUTIERREZ-ADAN, A. Epigenetic differences between male and female bovine blastocysts produced in vitro. Physiological Genomics, v. 32, p. 264-272, 2008.

3. BERMEJO-ÁLVAREZ, P.; RIZOS, D.; RATH, D.; LONERGAN, P.; GUTIERREZ-ADAN, A. Sex determines the expression level of one third of the actively expressed genes in bovine blastocysts. Proceedings of the National Academy of Sciences, v. 107, n. 8, p. 3394-3399, 2010.

4. BERTOLINI, M.; BEAM, S. W.; SHIM, H.; BERTOLINI, L. R.; MOYER, A. L.; FAMULA, T. R.; ANDERSON, G. B. Growth, development, and expression by in vivo- and in vitro-produced day 7 and 16 bovine embryos. Molecular Reproduction and Development, v. 63, p. 318-328, 2002.

5. BEYHAN, Z.; JOHNSON, L. A.; FIRST, N. L. Sexual dimorphism in IVM-IVF bovine embryos produced form $X$ and $Y$ chromosome-bearing spermatozoa sorted by high speed flow cytometry. Theriogenology, v. 52, p. 35-48, 1999.

6. CRAN D. G.; JOHNSON, L. A.; POLGE, C. Sex preselection in cattle: a field trial. Veterinary Record, v. 136, p. 495-496, 1995

7. DEAN, W.; SANTOS, F.; STOJKOVIC, M.; ZAKHARTCHENKO, V.; WALTER, J.; WOLF, E.; REIK, W. Conservation of methylation reprogramming in mammalian development: aberrant reprogramming in cloned embryos. Proceedings National Academy of Sciences, v. 98, p. 13734-13738, 2001.

8. FOOTE, R. H.; MILLER, P. What might sex ratio control mean in animal world? In: KIDDY, C. A.; HAFS, H. D. (Ed.). Sex ratio at birth prospects for control: a symposium. Champaign: American Society of Animal Science, 1971. p. 1-9.
9. GARNER, D. L. Flow cytometric sexing of mammalian sperm. Theriogenology, v. 65 , n. 5, p. $943-957,2006$

10. GARNER, D. L.; GLEDHILL, B. L.; PINKEL, D.; LAKE, S.; STHEPHENSON, D.; VAN DILLA, M. A.; JOHNSON, L. A. Quantification of the $X$ - and Y-chromosome-bearing sperm of domestic animals by flow citometry. Biology and Reproduction, v. 28, p. 312-321, 1938.

11. GARNER, D. L.; SEIDEL JR., G. E. History of commercializing sexed semen for cattle. Theriogenology, v. 69, p. 886-895, 2008.

12. GUTIÉRREZ-ÁdAN, A.; BEHBOODI, E.; MURRAY, J. D.; ANDERSON, G. B. Early transcription of the SRY by bovine preimplantation embryos. Molecular Reproduction and Development, v. 48, p. 246-250, 1997.

13. GUTIÉRREZ-ÁDAN, A.; RIZOS, D.; FAIR, T.; MOREIRA, P. N.; PINTADO, B.; DE LA FUENTE, J.; BOLAND, M. P.; LONERGAN, P. Effect of speed of development on mRNA expression pattern in early bovine embryos cultured in vivo or in vitro. Molecular Reproduction and Development, v. 68, p. 441-448, 2004.

14. HENDRIKSEN, P. J. M. Do $X$ and $Y$ spermatozoa differ in proteins? Theriogenology, v. 52, n. 8, p. $1259-1307,1999$

15. JIMENEZ, A.; MADRID BURY, N.; FERNANDEZ, R.; PEREZ-GARNELO, S.; MOREIRA, P.; PINTADO, B.; DE LA FUENTE, J.; GUTIÉRREZ-ÁDAN, A. Hyperglycemia-induced apoptosis affectes sex ratio of bovine and murine preimplantation embryos. Molecular Reproduction and Development, v. 65, p. 180-187, 2003.

16. JOHNSON, L. A.; FLOOK, J. P.; LOOK, M. V.; PINKEL, D. Flow sorting $X$ and $Y$ chromosome-bearing spermatozoa into two populations. Gamete Research, v. 16, p. 1-9, 1987.

17. JOHNSON, L. A.; FLOOK, J. P.; HAWK, H. W. Sex preselection in rabbits: live births from $X$ and $Y$ sperm separated by DNA and cell sorting. Biology and Reproduction, v. 41, p. $199-203,1989$.

18. JOUDREY, E. M.; LECHNIAK, D.; PETRIK, J.; KING, W. A. Expression of growth hormone and its transcription factor, Pit-1, early bovine development. Molecular Reproduction and Development, v. 64, p. 275-283, 2003.

19. KIDDER, G. M. The genetic program of preimplantation development. Developmental Genetics, v. 13, p. 319-325, 1992.

20. KIDDY, C. A.; HAFS, H. D. Sex ratio at birth - prospects for control. Savoy, IL: American Society of Animal Science, 1971.

21. KLINC, P.; RATH, D. Applications of flowcytometrically sexed spermatozoa in different farm animal species: a review. Archiv für Tierzucht, v. 49, n. 1, p. 41-54, 2006.

22. LIMA, V. F. M. H. Espermatozóide sexado bovino: quando utilizá-lo? Acta Scientiae Veterinariae, v. 34, p. 213-224, 2006.

23. LU, K. H.; CRAN, D. G.; SEIDEL JR. G. E. In vitro fertilization with flow-cytometrically sorted bovine sperm. Theriogenelogy, v. 52, p. 1393-1405, 1999

24. LU, K. H.; SEIDEL JR., G. E. Effects of heparin and sperm concentration on cleavage rates of bovine oocytes inseminate with flow-cytometrically-sorted bovine sperm. Theriogenology, v. 62, p. 819-830, 2004.

25. LUCHIARI FILHO, A. L. Produção de carne bovina no Brasil. Qualidade, quantidade ou ambas? In: SIMPÓSIO SOBRE DESAFIOS E NOVAS TECNOLOGIAS NA BOVINOCULTURA DE CORTE, 2, Brasília - DF, 2006.

26. MAXWELL, W. M.; EVANS, G.; HOLLINSHEAD, F. K.; BATHGATE, R.; DE GRAAF, S. P.; ERIKSSON, B. M.; GILLAN, L.; MORTON, K. M.; O'BRIEN, J. K. Integration of sperm sexing technology into the ART toolbox. Animal Reproduction Science, v. $82-83$, p. 79-95, 2004

27. MEMILI, E.; FIRST, N. L. Zygotic and embryonic expression in cow: a review of timing and mechanisms of early expression as compared with other species. Zygote, v. 8, p. 87-96, 2000.

28. MERTON, J. S.; HARING, R. M.; STAP, J.; HOEBE, R. A.; ATEN, J. A. Effect of flow cytometrically sorted frozen/thawed semen on success rates of in vitro bovine embryo production. Theriogenology, v. 47, p. 295, 1997. 
29. MOHAN, M.; HURST, A. G.; MALAYER, J. R. Global expression analysis comparing bovine blastocysts flushed on day 7 or produced in vitro. Molecular Reproduction and Development, v. 68, p. 288-298, 2004

30. MOORE, K.; THATCHER, W. W. Major advances associated with reproduction in dairy cattle. Journal of Dairy Science, v. 89, p. 1254-1266, 2006.

31. MORTON, K. M.; HERRMANN, D.; SIEG, B.; STRUCKMANN, C.; MAXWELL, W. M. C.; RATH, D.; EVANS, G.; LUCAS-HAHN, A.; NIEMANN, H.; WRENZYCKI, C. Altered mRNA expression patterns in bovine blastocysts after fertilization in vitro using flow-cytometrically sex-sorted sperm. Molecular Reproduction and Development, v. 74, p. 931-940, 2007.

32. MOTA, A. V. Sexagem de espermatozóides em mamíferos domésticos. 2004. Dissertação (Mestrado) - Faculdade de Medicina Veterinária e Zootecnia, Universidade Estadual Paulista "Júlio de Mesquita Filho", UNESP-Botucatu/SP, 2004.

33. PALMA, G. A.; OLIVIER, N. S.; NEUMÜLLER, Ch.; SINOWATZ, F. Effects of sex-sorted spermatozoa on the efficiency of in vitro fertilization and ultrastructure of in vitro produced bovine blastocysts. Anatomy, Histology and Embryology, v. 37, p. $67-73,2008$

34. PETER, A. T.; JONES, P. P.; ROBINSON, J. P. Fractionation of bovine spermatozoa for sex selection: a rapid immunomagnetic technique to remove spermatozoa that contain the HY antigen. Theriogenology, v. 4, n. 6, p. 1177-1185, 1993.

35. PINKEL, D.; LAKE, S.; GLEDHILL, B. L.; VAN DILLA, M. A.; STEPHENSON, D.; WA TCHMAKER, G. High resolution DNA content measurements of mammalian sperm. Cytometry, v. 3, p. 1-9, 1982.

36. RATH, D.; JOHNSON, L. A. Application and commercialization of flow cytometrically sex-sorted semen. Reproduction in Domestic Animals, v. 43, p. 338-346, 2008.

37. SEIDEL JR., G. E. Economics of selecting for sex: the most important genetic trait. Theriogenology, v. 59, p. 585-598, 2003

38. SEIDEL JR., G. E. Sexing mammalian sperms and embryos. In: INTERNATIONAL CONGRESS ON ANIMAL REPRODUCTION AND ARTIFICIAL INSEMINATION, 11 1988, Dublin. Proceedings ... Dublin: University College Dublin, 1988. p. 136-144.

39. SEIDEL JR., G. E.; CRAN, D. G.; HERICKHOFF, L. A.; SCHENK J. L.; DOYLE, S. P.; GREEN, R. D. Insemination of heifers with sexed sperm. Theriogenology, v. 52, $p$ 1407-1420, 1999

40. SIQUEIRA, K. B.; CARNEIRO, A. V. (Coord.). Conjuntura do mercado lácteo. Boletim Eletrônico Mensal, EMBRAPA Gado de Leite, v. 5, n. 44, 2012. Disponível em: <http://www.cileite.com.br/sites/default/files/2012_10_Produ\%C3\%A7 \%С3\%A3o_Leite.pdf> Acesso em: $01 \mathrm{dez} .2012$.
41. SUMNER, A. T.; ROBINSON, J. A. A difference in dry mass between the heads of $X-$ and $Y-$ bearing human spermatozoa. Journal of Reproduction and Fertility, $v$. 48 , n. 1, p. 9-15, 1976.

42. TELFORD, N. A.; WATSON, A. J.; SCHULTZ, G. A. Transition from maternal to embryonic control in early mammalian development: a comparison of several species. Molecular Reproduction and Development, v. 26, p. 90-100, 1990.

43. TRIGAL, B.; GÓMEZ, E.; CAAMAÑO, J. N.; MUÑOZ, M.; MORENO, J.; CARROCERA, S.; MARTÍN, D.; DIEZ, C. In vitro and in vivo quality of bovine embryo in vitro produced with sex-sorted sperm. Theriogenology, v. 78, p. 1465-1475, 2012.

44. VIGNEAULT, C.; MCGRAW, S.; MASSICOTTE, L.; SIRARD, M. A. Transcription factor expression patterns in bovine in vitro-derived embryos prior or maternal-zygotic transition. Biology of Reproduction, v. 70, p. 1701-1709, 2004.

45. WHEELER, B. M.; RUTLEDGE, J. J.; FISCHER-BROWN, A.; VANETTEN, T.; MALUSKY, S.; BEEBE, D. J. Application of sexed semen technology to in vitro embryo production in cattle. Theriogenology, v.65, n.1, 219-227, 2006.

46. WILSON, R. D.; FRICKE, P. M.; LEIBFRIED-RUTLEDGE, M. L.; RUTLEDGE, J. J.; SYVERSON PENFIELD, C. M.; WEIGEL, K. A. In vitro production of bovine embryos using sex-sorted sperm. Theriogenology, v. 65, p. 1007-1015, 2006.

47. WRENZYCKI, C.; HERRMANN, D.; CARNWATH, J. W.; NIEMANN, H. Alterations in the relative abundance of transcripts in preimplantation bovine embryos cultured in medium supplemented with either serum or PVA. Molecular Reproduction and Development, v. 53, p. 8-18, 1999

48. WRENZYCKI, C.; HERRMANN, D.; LUCAS-HAHN, A.; KORSAWE, K.; LEMME, E.; NIEMANN, H. Messenger RNA expression patterns in bovine embryos derived from in vitro procedures and their implications for development. Reproduction, Fertility and Development, v. 17, p. 23-35, 2005

49. WRENZYCKI, C.; HERRMANN, D.; NIEMANN, H. Messenger RNA in oocytes and embryos in relation to embryo viability. Theriogenology, v. 68, p. 77-83, 2007.

50. WRENZYCKI, C.; LUCAS-HAHN, A.; HERRMANN, D.; LEMME, E.; KORSAWE, K.; NIEMMAN, H. In vitro production and nuclear transfer affect dosage compensation of the X-linked transcripts G6PD, PGK, and Xist in preimplantation bovine embryos. Biology of Reproduction, v. 66, p. 127-134, 2002.

51. WRENZYCKI, C.; NIEMANN, H. Epigenetic reprogramming in early embryonic development: effects of in vitro-production and somatic nuclear transfer. Reproductive Biomedicine Oline, v. 7, p. 649-656, 2003.

52. ZHANG, M.; LU, K. H.; SEIDEL, G. E. Development of bovine embryos after in vitro fertilization of oocytes with flow cytometrically sorted, stained and unsorted sperm form different bulls. Theriogenology, v. 60, p. 1657-1663, 2003 